
\title{
25 Research Square \\ Potential role of holobiont nitrogen control in jellyfish eutrophication resistance
}

\section{Till Röthig \\ Giulia Puntin \\ Jane C. Y. Wong \\ Alfred Burian \\ Wendy McLeod \\ David M. Baker}

\section{Video Byte}

Keywords: stable isotope analysis, tracer, bacterial profiling, environmental resilience, 16S rRNA gene, cnidarian, jellyfish, upside-down jellyfish, Cassiopea xamachana, isotopic labelling, eutrophication, Symbiodiniaceae, algal symbiont, photosymbiosis, Microbiome, nutrient cycling, nutrient assimilation, dissolved inorganic nitrogen, DIN, metabarcoding

Posted Date: October 14th, 2021

DOI: https://doi.org/10.21203/rs.3.rs-968142/v1

License: (c) (i) This work is licensed under a Creative Commons Attribution 4.0 International License.

Read Full License 


\section{Abstract}

The relationships between cnidarians such as corals and their symbiotic microbes, including algae, bacteria, and other microorganisms, are key to reef health. However, along with ocean warming, eutrophication threatens these relationships by overwhelming the algal symbionts with dissolved nutrients. Some cnidarians with symbionts, including certain jellyfish, are very tolerant of eutrophication, and understanding these host-symbiont units (holobionts) could provide insights for reef preservation. A recent study investigated nutrient cycling in the eutrophication-resistant upside-down jellyfish. Isotope labelling revealed that the jellyfish shared carbon and nitrogen from food with their algal symbionts, but the algae had very limited access to nitrogen dissolved in the water. According to DNA metabarcoding, symbiotic jellyfish had lower bacterial diversity than algae-depleted (aposymbiotic) jellyfish, and lower diversity was correlated with lower nitrogen assimilation. Notably, functional analysis suggested that the bacterial community in the symbiotic jellyfish was optimized to restrict the algae's access to dissolved nitrogen. Although the exact cooperative mechanisms remain unclear, these findings indicate that the host, algae, and bacterial microbiome all work together to regulate nutrient cycling and prevent algal nitrogen overload during eutrophication, indicating the importance of the microbiome in stabilizing hostalgae symbiosis in this jellyfish species. 